\title{
3. 'Letting them eat cake': Narrative templates in current affairs/news journalism
}

\section{ABSIRACII}

This article explores the role of narrative templates in a core domain of public communication, describing a series of narrative structural patterns that underlie the scripting of news and current affairs 'reports'. From an initial account of the nature of narrative templates and their relation to audience expectations and interpretative regimens, a number of specific story-styles that are employed recurringly in news programmes are described, examining their use and impact for capturing and maintaining audience attention. The process of telling the audience the stories it wants to hear is critiqued in terms of the capacity to subvert the quality of public communication and in terms of enduring concerns within discursive theory.

Keywords: audience attention, discursive theory, narrative templates, public communication

\section{JOHN CARR}

University of Technology, Sydney

7 HE THEME questions for the 2008 Public Right To Know conference in Sydney raised issues which may undermine or compromise that

1 public right, with the formal title of the conference 'Giving the People What They Want' specifically appearing to recognise that simply giving the public what they want might be a core factor which disrupts this right-toknow.

This article explores the role of narrative templates in a core domain of public communication, describing a series of narrative structural patterns that underlie the scripting of news and current affairs 'reports' and is premised on the simple and obvious notion that much of what is presented in 'News' 
and 'Current Affairs' programmes panders more to what the public wants to view or know and experience, rather than seeking to serve what it may need to know so as to be able to function effectively as a public. The central proposition of this article that the public is too often being told old stories, with new events wrapped around and at times submerged within older recurring narrative themes - or to put it another way, the digitally mediated technologies of public communication may be new, but it is usually the same old stories that they tell.

From an initial account of the nature of narrative templates and their relation to audience expectations and interpretative regimens, a number of specific story styles that are employed recurringly in news programmes are described, examining their use and impact for capturing and maintaining audience attention. The process of telling the audience the stories it wants to hear is critiqued in terms of the capacity to subvert the quality of public communication and in terms of enduring concerns within discursive theory, including the potential role of narrative to engender forms of social cohesion that may serve to sustain a public sphere.

\section{Narrative templates and interpretive schemas}

Narrative templates may be understood as organised clusters of elements, or even as standardised story-structures, which provide a model or shape from which to fashion later narratives. Templates may be considered as being similar functionally to a trellis upon which one might plant vegetables or vines, or like the scaffolding, the structures erected to facilitate erecting a building, or a prepared pattern for making a shirt or skirt.

Here we will simply note the nature of narrative templates as functioning as structures for creativity, recognising that this occurs in standard understandings of stories, not only in the framing of news items but in other story forms such as the creation of advertisements, the telling of history, the making of humour, and even in other forms of creativity such as musical composition.

A writer of tales today might be familiar with templates, especially given that so much modern writing is undertaken via the Microsoft Word programme which is structured so that every document is based on a template, entailing a foundational structure of default settings for formatting, fonts, menus, particular purposes (such as letters and invoices) page layouts and so on.

We are dealing here, however, with a form of narrative gestalt, wherein templates tend to function as a unified whole, a relatively standardised pattern 
or configuration of relationships between story characters and happenings. The elements of a narrative template may be character-types, such as a hero (always?) and a villain/opposer, or as is increasingly the case over the last c.150 years, a 'love-interest'. Elements may also be categories of events such as a disaster, or rescue, or partings, or misunderstandings, and even 'the chase'. Elements might also be archetypal places, such as a home to come back to, or to leave, or paradise, or a wilderness, or deep cavern, with places of peace or of mystery and danger. In Vladimir Propp's (1968) study of a hundred Russian folk tales he noted that despite surface differences in names and other details such as place and chronology, some basic underlying narrative structures emerged repeatedly, leading him to identify seven recurring spheres of action and 31 fixed elements. That such recurring structures actually constitute a story-making algorithm is evidenced in the creation of two 'fairy-tale generator' computer programmes which have been developed based on combining such narrative building blocks. (See for example the 'Proppian Fairy Tale Generator' and the 'Proppian Folktale Outline Generator v1.0']

Propp pursued the perspective that the study of folklore imitated that of organic nature in that both involved concepts of species and their variations. The identification of recurring species or structures of discourse arose essentially from the linguistic analyses of Ferdinand de Saussure whose structuralist approach was advanced further by the anthropological research of Claude Levi-Strauss who found that the myths of quite diverse cultures revealed repetitive structures. Although Hogan (2003) argues that there are just three paradigm narratives. He notes that to a large degree the narrative universals that emerge from structural analyses are concerned with those fundamental social-psychological issues and emotional states that we humans can expect to experience during our life, confronting those predictable life-tasks regarding partnering, conflict, birth, and death.

While the specific number of structures underlying templates may be disputed, they vary in other predictable ways according to what we usually understand as the genre of the story. Thus it is expected, for example, that a crime-story has a structure requiring specific elements such as at least a crime, an accumulation of evidence, with a form of consummation-and this is where another shaping device, which may be discussed elsewhere as the cultural narrative template, comes to impinge itself on the genre, in that the consummation may take the form of an arrest, or trial, if presented in a 
British or European telling, or - if it is an American movie - then perhaps the consummation is simply a vengeful punch-up or shoot-out by the righteously indignant cop. We would all be familiar with other genres such as the lovestory, the triumph-against-odds, the 'whodunit' stories of revelation and the uncovering of the solution to a mystery.

That the public is mindful of such templates, carrying them as a pattern of expectation within their mind, influences them in a variety of ways. For a start, that moment of recognition as the audience realises what type of story it is encountering, allows them to move into an appropriate mood of receptivity and resonance, and it engenders particular expectations about what they may soon be feeling. It also provides a means by which the audience may evaluate how good the story is, which is often a matter of how well it meets their expectations by fitting with similar previous stories - and this is a matter which may powerfully determine whether an audience persists in giving attention to the story; such attention to be on-sold to advertisers.

Because of the power of narrative templates, story-making is much like that oft-heard phrase in cooking programmes: "Here's one I prepared earlier". Yet it is not only that a story may have had an earlier creation, so too is the audience 'prepared'. What do we have after hearing a news-story? Hopefully some degree of retention of the content. But before we hear the story, is there really nothing? Can an audience encounter a story in a state of total naivety or even openness? Here we can consider the notion of protension. In essence, this refers to the fact that when we begin to engage with a text, we do so with a schema of expectations. Much of the power of intertextuality resides in $t$ his phenomenon. Thus whereas narrative coherence (Fisher, 1984) is typically understood as the degree of compatibility or consistency of parts of a story with its other parts, yet it is also a matter of how well the story matches the recurring elements of previous stories of the particular genre. Interestingly, the element of surprise which is so often favoured by Hollywood scriptwriters and others, typically involves a paradox whereby a particular expectation is firstly activated and then substituted for another: for example, what at first looked like a love-story might become a murder mystery. Such shifting or blending (Fauconnier \& Turner, 2003) among templates might appear to undermine the power of expectation which they engender, but in fact it is totally dependent upon the existence and shaping-influence of such expectations, else there would be no surprise. 
Templates in general are extremely relevant to how we form an understanding and evaluation of experience, such that acts of interpretation may be viewed as a process of seeking evidence of equivalence between different areas of representations. What does this mean? That essentially acts of understanding and interpretation are premised upon analogies and metaphors, in that they rely upon a juxtaposition of the elements or structures of two conceptual domains. In their account of the prevalence of conceptual blending, Fauconnier and Turner pursue the notion of a fundamentally metaphorical substrate to creative thinking. That is, to make sense of something in the world, we begin by seeking analogies with the already existing models of knowledge which we carry within as a result of our cultural programming and input, and our own capacity to make sense of the world. As cognitive psychology keeps rediscovering, human beings are repeatedly watching old movies in their heads even when they are attempting to comprehend a new reality.

\section{Templates in current affairs/news}

Accordingly, for the voyeurs of public television, it is easy to see evidence of recurring narrative forms in public communication endeavours such as 'News' and 'Current Affairs' programmes. While there are some smaller recurring narrative forms, such as 'the menace to society', 'youth gone wild', 'hopeful medical breakthroughs', 'diets', 'freaks' (of nature and persons), various promotions, whetherforcelebrityunderwearor theubiquitous cross-promotions of other television programmes, yet further major narrative templates may also be identified.

This article will describe five of these recurring templates, specifically, 'David vs Goliath', 'Transformation' stories, 'Just Deserts', 'Moral Drama', 'Reassurance/Comfort',

Repeatedly, many of the individual stories presented in such programmes can be seen to centre around a number of core story frames such as 'David vs Goliath', in which a small and relatively powerless person or group fights the valiant fight against more powerful and larger vested interests: our emotions are usually meant to be aligned with the David character, and the television presenter, who paradoxically is in reality also a representative of a larger and very powerful entity, sides with the smaller individual, and with the viewers in their struggle against big business, or encroaching government. We may note that Ray Martin, the most pre-eminent of such presenters in recent 
Australian media, is known as 'the battler's friend'. Here we may recognise the ongoing drama of Channel 9's programme A Current Affair versus local government councils, in which the programme recurringly presents items in which it aligns itself in support of relatively powerless individual citizens framed as underdogs who are in disagreement with the decisions and actions of their more powerful local council.

'Transformation' stories may also be noted. Here we have stories of a transition from rags to riches, from log-cabin to mansion (or White House), from ill-health to recovery. While such stories convey a transformation enacted over time, the 'Ugly Duckling' or 'Good Samaritan' genres also convey a transformation, but this time a change which usually occurs within the perception of others. Hence a despised person is rediscovered as one found to be worthy of respect, a rejected outsider becomes welcomed and accepted, people come to be seen in their true and valued colours. Here too we encounter the preoccupation in current affairs programmes with facial and bodily enhancements such as plastic surgery, Botox treatments, and weight-loss regimes. Many of the popular portrayals of 'medical wonders' also fit within the Transformation category, as for example a news item showing a young man before and after neurological surgery to ameliorate Tourette's syndrome: from firstly having a persona that is frequently despised, feared, and treated as alien within the community; the post-operation footage shows a more likeable and normal young adult. The community-building meta-message here is essentially a valuing of inclusiveness, conveying both hope to those who are currently despised or rejected (for example, the anorexic and the obese), and also encouraging tolerance to those who previously may have been dismissive of the compromised outsiders. At its simplest, the 'Transformation' narrative template offers assurance that 'there is light at the end of the tunnel'.

The 'Moral Drama' is a favourite of ratings-conscious producers, since the degree to which they can harness the passions of the moral outrage, anger, and negative judgements of their audience, especially through inciting moral panics, tends to guarantee that they will retain the attention of that audience. Of course the real business here is the on-selling to the advertisers of the program of the suitably aroused attention and consciousness of a segment of the public. The seminal delineation of the moral panic phenomenon is Cohen's (1972) study of the role of the mass media in amplifying the deviancy and polarisation between the 'Mods' and 'Rockers' in the United Kingdom, 
amplified further in studies of the media portrayal of other marginalised groups of the time such as drug-users, gays, and political protesters (Cohen \& Young, 1981). The current favourite focus for such scare-campaigns tends to concern pedophiles, but other groups framed as being social outcasts involve liminal or marginalised characters such as 'boat-people', 'dole-bludgers', fraudsters and other criminals, and in other times and places have demonised witches, Jews, homosexuals.

The potential social consequences of such narratives are noted in Turner's (1981) theory that 'social dramas' are the means by which individuals and societies define or redefine their beliefs. Typically, according to Turner, the standard social drama involves a sequence through four acts: firstly a breach, its resultant crisis, a redress, and lastly a resolve or settlement involving either reintegration (the 'Transformation' template) or in consolidation of the social schism. Underlying such dramas are conditions in which there is transgression of the normative rules, but the threat to these serves also to clarify the social mores and assure the audience of the reintegration of social values.

From their recent research into coalition-building strategies enacted in the contest for nomination as the Democratic Party presidential candidate between Barack Obama and Hilary Clinton, Zhong et al. (2008) showed that there are significant consequences arising from whether people identify themselves through either an affirmational or negational basis for group-affiliation. Whereas affirmationally-based identity involves noticing one's similarity to an in-group, negational identity involves people defining themselves through differences that contrast them with outsiders. On the purely mathematical demographics of the fact that for any one social group there are usually more people who are not in that group compared to those who are, then such negational identity has been found to offer a more extensive basis for building a sense of coalition, uniting in shared and usually hostile opposition all those who do not belong to the same group. Australian politics is not unfamiliar with attempts to build a sense of community by creating a common enemy, demonising and despising some outsiders. As suggested so insightfully in series three of the earlier satirical Frontline television programme screened by the ABC (Cilauro et al., 1995), featuring a story of a family of unemployed teenagers in which the producer seeks to fuel the community outrage ('So we fix the perception?' asks Emma. 'No', replies Prowse, 'we feed it.'), a story which caricatured an earlier episode from Channel 9's A Current Affair. This 
'Harness the Hate' phenomenon is a form of media manipulation of public passion which is a powerful strategy for capturing audience attention. That is, programmes that focus on that warm inner glow of belonging may certainly appeal to viewers, but a moral outrage tends to engender a stronger sense of heated passion, uniting them against the threat of the rejected other. Significant here is the evidence advanced by Poynting and Noble (2003) of the tabloid portrayal of Australian Muslims as instances of 'dog-whistle politics' appealing to xenophobic insecurities and thus reinforcing 'us-vs-them' community attitudes. On the surface then the 'Moral Drama' template with its focus on social exclusion may certainly be viewed as opposing the inclusiveness of the 'Transformation' template, yet both offer the audience the opportunity to reinforce their sense of participation in and identity with their preferred version of what Anderson (1991) has termed their own 'imagined community'.

Television news-programmes often feature a 'Just Deserts' format, presenting stories of people who are either rewarded for their kind and giving natures, or others who finally meet justice for their dire deeds. Accordingly, current affairs programmes are rife with repeated scenes of someone thrusting their hands in front of the camera-lens as they seek to escape being identified as someone exploiting or manipulating the general public. This template naturally pre-supposes the 'Moral Drama' template, as both focus upon notions that societal harmony and security may be disrupted, the latter template purporting to label those who are deviant, and the 'Just Deserts' template seeking to restore the audience's sense of safety. That the public experiences a hunger for justice signals that the community-building message underpinning this template is that of normative re-establishment: in its suggestion that the rule-breakers will be discovered, then in many ways this is also a Reassurance format.

Many 'News' programmes like to complete their nightly coverage of the disasters and crises of the world with a 'Reassurance/Comfort' story: the cat is rescued from the tree, a new baby animal is safely born at the zoo, a kindhearted local celebrity receives an award. The meta-message here is typically conveyed through the reaction of the presenter, who, despite having seen the crime and carnage and corruption of the world, can at the end of it all still have something to smile about, leaving the viewers reassured that the world might still be a safe and comfortable place, or that they can retire feeling at least that they do not have to do anything about it. It is this latter which is perhaps the most insidious: if Karl Marx were with us today perhaps he would rail against 
television, identifying it rather than religion as 'the opiate of the masses', or as I would frame it, as 'visual valium', given its power to render the public into passive recipients rather than active constituents of a democracy as they become merely 'couch-potato' spectators of the corruption of the world, rather than knowing how they could harness their concerns into a reforming power. Stories always call forth a response from us, but sometimes they may only mollify us into inaction.

\section{Critiquing/appreciating narrative in the public domain}

It is perhaps this process of passivication of the polity that most engenders concern that the media contributes to the subversion of the public sphere. For Carpignano et al $(1990$, p. 37) the manipulative invasion of public relations strategists renders the media as a 'tranquilising substitute for action'. Fine and White argue that while a 'human interest' story may serve to promote social identification, yet it diverts attention from the political dimension and so 'erases politics and policy. In this, identification is consistent with political passivity...' (2002, p. 77).

Such concerns resonate with Thompson's recognition that the mediasation of modern culture is actively and rapidly changing the nature of society, that 'the transmission of symbolic forms becomes increasingly mediated by the technical and institutional apparatuses of the media industries' (1990, p. 25). The argument by Dahlgren in his book Television and the Public Sphere: Citizenship, Democracy and the Media (1995) was that the media have become a central force in modern culture with the power to transform the nature of the public sphere and hence civil society and democracy; he shows that television's status as the main theatre that stages public discussion means that viewership is not just a matter of consumption practices, but plays a core role in creating a sense of citizenship.

Some of the potential dangers inherent in this mediasation were noted almost half a century ago when Daniel Boorstin described what he termed the 'Graphic Revolution', a time in which our technologies for altering and disseminating images had begun to create a 'thicket of unreality which stands between us and the facts of life' (1961, p. 3), functioning as 'illusions with which to deceive ourselves' (p. 5). For Boorstin, 'In this new world, where almost everything can be true, the socially rewarded art is that of making things seem true' (p. 212). A cunning tool in this process involves the fabrication of 'pseudoevents', or what Kellner (2003) calls 'megaspectacles', 
that are contrived to attract audience attention by being 'more vivid, more attractive, more impressive, and more persuasive than reality itself' (p. 36). Other social theorists have advanced similar notions, suggesting that the link between what is represented and any notion of 'the original' has become increasingly problematic. Debord (1967) took up this same theme and argued that we live in a 'society of the spectacle', riven through with attractive and compelling yet counterfeit illusions, and Baudrillard (1983) later described our immersion in 'simulacra' and hyperreality in which much of what we really encountered was simply a synthetic reality of 'pure floating images', behind which there is nothing.

From such descriptions arises the concern that professional communicators such as journalists, politicians, and even historians, may be diverted from being transmitters of truth into becoming simply purveyors of performances. Thus Bennett's analysis (1996) of media coverage of a British national election is appropriately titled 'Camera, Lights Action' — and is positioned within a journal oriented to folklore. In response to such concerns, a number of theorists have developed models of 'discursive democracy' (Dryzek, 1994; Gutman \& Thompson, 1996), seeking to elucidate the communicational qualities that may support and sustain a viable and democratic polity. In accenting the communicative dimensions of national political consciousness, the enduring pro-media argument has been that public media-participation transforms individuals into engaged citizens, the media occupying a central and powerful role, typically cast as the modern agora, a supposedly free marketplace of ideas. In contrast, the analysis of the public discourse concerning media-violence following the massacre of 35 Australian citizens at Port Arthur in 1996 showed that what passes as 'the public discourse' concerning media effects was conducted in such a manner as to effectively exclude or mute the voice and thus the perspectives and preferences of the public: in essence, what the sampled public identified as the predominant viewpoint in that debate was a 'media-apologist' voice which defended the media against claims of having a negative societal impact, while the public itself dissented strongly, showing a clear rejection of that apologetic stance (Carr, 1996a, 1996b). This underscores the importance of the question raised by Bird and Dardenne (1988) as to 'whose values are encoded in news-whose stories are being told' (1988, p. 79).

Iris Young (2000) critiques pro-media models of discursive deliberation on the grounds that they tend to privilege modes of engagement that are 
dispassionate and disembodied, accenting reason while denigrating affective engagement, favouring neutral and calm cognition while distrusting excited emotional expression. Young's view that such communicational preferences supposedly reflect the speech practices of white, middle class males, and thus foster differences of social privilege over women and racial or class groups, reflects the Foucauldian identification of the power relations underpinning discourse and knowledge.

Yet more generally from Young's dichotomy I would suggest that we can derive the broader recognition that theorising concerning the public sphere has tended to promote the shared general values of theorists: the academic values of those institutionalised spectators of the public spectators. Thus Habermas' description of an 'ideal speech situation' is essentially a dispassionate encounter between informed minds oriented to facts. In their delineation of conceptualisations of the public sphere Ferree et al. (2002) note that the predominant models of the public sphere emphasise a variety of core values such as accuracy, objectivity, transparency, empowerment, symmetricality, inclusiveness, and reasoned moral deliberation. Ferree et al. also note that only the constructionist approach accords any value to the role of narrative, particularly affirming that narratives as a communicational form offer an opportunity to bridge the standard chasm between the sphere of formal politics and the experienced socially-located lifeworld (or what German exegeticists term the 'lieb in sitz') of persons who are more than just citizens. Cebik (1986) notes that in Ricoeur's account of history as being in general a form of narrative there is the notion that narrative creations revolve around and always return to the concerns and presuppositions of everyday life.

This returns us to Fine and White's work (2002) that recognises the power of human interest stories to engender shared social identification, and thus to encourage the social cohesion that is required to maintain a public sphere. Ferree et al. note that most issues in the public realm that arouse heightened moral concerns typically involve ambiguity about who is or who is not acceptable to be included within a community, for which Young presents the perspective that narrative serves as a significant and even desirable form of public discourse because of its power to generate shared understanding across domains of social distance and difference.

In the more positive manifestation of the role of the media as deduced by Dahlgren, television is viewed as having a capacity to encourage citizenship primarily by disseminating knowledge and catalysing informed 
communication about social issues: but the notion advanced in this article is that television news and current affairs broadcasting may be fostering a sense of community, not by generating informed fact-based discussion, but more by reminding the public of their shared story-forms. That is, as supposedly 'new' stories become aligned with or subsumed into older pre-existing narrative templates that reflect communal values, aspirations, and concerns, then the public is not just passively consuming old stories but is enticed into a participation event. Whereas Ong's (1982) model of an evolutionary transition through differing modes of communication is often taken to presume that earlier modes have diminished, yet it may be argued that the appeal of earlier forms persists: as our ancient ancestors gathered around camp-fires hearing the old stories, so we as inheritors of that 'stone-age mind' (Allman, 1994; Donald, 1991) now lounge in front of the flickering radiance of the screen to share the 'old old stories'. Having that collection of shared stories, having current affairs interpreted through those pre-existing narrative templates, becomes then a powerful means of social bonding, the flickering screen and the anchor-person/narrator serving to shape our imagined community. Ultimately however, we can say that those current affairs programmes that are typically scheduled to follow the 'News' should more rightfully be titled the 'Olds': A Current Affair often becomes just a recurring affair, and Today Tonight is a matter of 'same old same old', any day, any night.

From Habermas onward we have focused on a model of societal communication premised on the notion that a public sphere arises from and so depends upon the availability of information as news. Appropriately, for any group seeking social justice, this perspective arouses a concern to allow and sustain the unfettered dissemination of public information, and given that the accepted wisdom has been that modern media constitutes that public sphere, then there has also been a concern that the media's focus on entertainment values has served to subvert rational public discourse. As put two decades ago by Postman (1987), a result of this privileging of entertainment has been the notion that 'there's no business but show business', such that serious public issues involving matters ethical and political become transformed simply into gladiatorial clashes between talking heads. Accordingly, an ongoing protest for those concerned with the quality of the public sphere has been to challenge those media practices which degrade or divert attention away from the dissemination of objective realistic information. Frus (1994), for example, notes the 'border-crossing' nature of journalism, its practitioners engaging with 
matters of fact while drawn to genres of fiction, straddling that narrative space between 'the timely and the timeless'. The primarily academic pre-occupation with an informational version of the public sphere thus clashes somewhat with alternative models of public communication-views such as Carey's (1989) — which accent the ritualistic functions of shared communication.

Marita Sturken $(1997,2002)$ sees such ritualistic forms of communication operating in the formation of cultural memories. From her study of events such as the Vietnam War, she proposes that how cultures commemorate significant historical episodes has more to do with supporting the continuation of cultural values in the present than with any regard for retaining an original or actual reality. That is, cultures have stories that they see as worth telling, and since worth is a values-issue, then there are some values that the culture may regard as more important than truth.

This is reminiscent of the proposal advanced by David Friedrich Strauss (1970/1835), that great early myth-buster of Christianity, in his notion that the gospel stories were intended to offer insights into 'spiritual truths' rather than into merely historical facts, such that the gospel scriptwriters pursued what they viewed as the nobler task of writing 'sacred myth', choosing to engage in the concoction of stories capable of appealing to and transforming others, as compared to simply informing them of the facts of history. Cultural memory then is a process of enveloping the participants further into the webs of meaning that are currently central to the culture: more than simply connecting them with an historical past, commemorations are a means to engender deeper membership and participation in the cultural values that characterise the present. Sturken notes regarding cultural memory that, 'Its authenticity is derived not from its revelation of any original experience but from its role in providing continuity to a culture, ... it integrates fantasy, invention, and reenactment, that it is a process of engaging with the past rather than a means to call it up ...' (1997, p. 259). Effectively, Sturken's work serves to underscore the recognition that cultural commemorations serve a political and not just historical function, playing a salient role in shaping and reinforcing national identity. Again then, stories trump news.

Similarly, Sarah Maza (1996) drew attention to the political consequences of the fact of individual subjectivity arising from communally shared sentimentality, drawing on the insight given in Milan Kundera's novel The Unbearable Lightness of Being (p. 74): noting that a shared emotional experience may elicit two tears. 'The first tear says: How nice to see children running on 
the grass! The second tear says: How nice to be moved, along with all mankind, by children running on the grass!' At a time when media organisations engage increasingly in market-segmentation and narrowcasting to cater to niche audiences, and when Bishop (2008) raises concerns that American democracy is becoming demographically and ideationally polarised, then having narratives that can be shared across social divisions may become especially significant for sustaining a basis for a 'communitarian' (Etzioni, 1993) collective identity: the alternative may be a polity riven by tribal chaos. Shared cultural narratives then may function as a theatre in which social crises and divisions may be resolved, allowing the negotiation of shared social meanings.

In a social structure in which the public has moved from being citizens to being viewers - much in the manner of Chauncey Gardiner in Kosinski's 'Being There' (1970) — 'I like to watch' — then public broadcasting is not a realm ruled only by the logic of syllogisms, nor by the faithful rendering of dispassionate fact, but also by the sentimentality of stories. In supposedly saying, 'Let them eat cake', Marie Antoinette was purportedly supporting the view that the public just wants 'bread and circuses', and while the public does require and deserve the right to know information, yet quite clearly the public does not demand 'Just the facts Ma'am'; rather to experience themselves as a public they require a feeling of participation in shared stories: that is, the public may want the right to accurately know exactly what goes into the recipe, but they want also the experience of eating the cake, and the media practice of transforming new stories by subsuming them within pre-existing narrative templates serves to let them eat that cake, and to make it tempting, tasty, and palatable. Certainly in modern times, with journalists positioned as 'the prototypical technical-intellectual of mass society' (Carpignano et al., p. 39), their institutional values such as accuracy and objectivity are accorded justifiable ethical status, and yet the inherent value of such modes of communication need not require disparagement nor rejection of those more narrative-based modes still favoured by the general public: in line with Carpignano et al., we can say that the ideology of the press may be objectivity, but the ideology of the public is shared humanity, for which objectivity may be a faithful though not always necessary servant.

\section{Conclusion}

In conclusion, we are returned to the question raised by Bird and Dardenne (1988) as to 'whose story?' and to their revaluing of the mythological 
function of news as narratives that offer a 'human ordering' such that 'News stories, like myths, do not "tell it like it is", but rather, "tell it like it means", (1988, p. 71). Accordingly, while it may be that 'Giving the People What They Want' in the form of 'Old Ways Of Telling' such as using narrative templates as shared conventions for story-telling in current affairs and news journalism may be a factor which disrupts the 'right-to-know', yet it may also be contended that such practices also foster a 'right-to-be', and perhaps more importantly, a capacity to 'be-with', thus to a degree serving to encourage and enhance that sense of social connectedness that may be essential to sustaining a public sphere. Certainly, given the media-machinations of Goebbels and others, it remains true that cultural manipulators may continue to harness the power of narrative templates to engineer social divisiveness, such that critical intelligent scrutiny of media story-telling practices will always be required. In essence however, if we truly value the sustaining of a viable public sphere that is equipped to address critical social, political, and environmental issues, then there first of all has to be a sense, a commonsense, of being united as a public, and so there may be a basis for revaluing those communicative forms such as narrative templates which engender in people a sense of participating together in shared story-telling.

\section{References}

Allman, William F. (1994). Stone age present: How evolution has shaped modern life - From sex, violence and language to emotions, morals and communities. New York: Touchstone Books.

Anderson, B. (1991). Imagined communities. London: Verso.

Baudrillard, J. (1983). Simulations. New York: Semiotext (e)

Bennett, G. (1996). Camera, lights, action! The British general election 1992 as narrative event. Folklore, 107, 94-97.

Bird, S. E. and R. W. Dardenne (1988). Myth, chronicle and story: Exploring the narrative quality of news. In Carey, J., Media, myths and narratives: Television and the press (pp. 67-86.) Newbury Park CA: Sage.

Boorstin, D.J. (1961). The image. New York: Vintage.

Carey, J. (1989). Communication as culture. New York and London: Routledge.

Carpignano, P., Andersen, R., Aronowitz, S., and Difazio, W. (1990) Chatter in the age of electronic reproduction: Talk television and the 'public mind' Social Text, 25/26. pp. 33-55.

Carr, J.E. (1996a). Making meaning of the media: Defence and dissent in the public discourse on media effects. Presented at The International Society for the Study of Subjectivity Conference, October 1996. Columbia: University of Missouri. 
Carr, J.E. (1996b). Mediasation and the muting of the public voice. Paper presented at the National Conference of the Australian Cultural Studies Association. December 1996. Fremantle, Western Australia.

Cebik, L. B. (1986). Understanding narrative theory. History and Theory, 25(4):,58-81.

Cerulo, Karen A. and Ruane, J. M. (1998). Coming together: New taxonomies for the analysis of social relations. Sociological Inquiry. 68, 398-425.

Cilauro, S., Kennedy, J., Sitch, R., Gleisner, T., and Zion, L. (1995). Frontline: The story behind the story... behind the stories. Ringwood, Vic: Penguin Books.

Cohen, S. (1972). Folk devils and moral panics: The creation of the Mods and Rockers. London: MacGibbon and Kee.

Cohen, S., and Young, J. (Eds). (1981). The manufacture of news: Social problems, deviance and the mass media. London: Constable.

Dahlgren, Peter (1995). Television and the public sphere: Citizenship, democracy and the media. London: Sage.

Donald, M. (1991). Origins of the modern mind. Cambridge, MA: Harvard University Press.

Dryzek, J.S. (1994). Discursive democracy: Politics, policy and political science. New York: Cambridge University Press.

Etzioni, A. (1993). The spirit of community: Rights, responsibilities and the communitarian agenda. New York: Crown Publishers.

Fauconnier, G. and Turner, M. (2003). The way we think: Conceptual blending and the mind's hidden complexities. New York: Basic Books.

Ferree, M.M., Gamson, W.A., Gerhards, J. and Rucht, D. (2002). Four models of the public sphere in modern democracies. Theory and Society, 31(3), 289-324.

Fine, G.A., and White, R.D. (2002). Creating collective attention in the public domain: Human interest narratives and the rescue of Floyd Collins. Social Forces. 81(1): 57-85.

Fisher, W.B. (1984). Narration as a human communication paradigm: The case of public moral argument. Communication Monographs 51, 1-22.

Frus, P. (1994). The politics and poetics of journalistic narrative: The timely and the timeless. Cambridge: Cambridge University Press.

Gutmann, A. and Thompson, D. (1996). Democracy and disagreement. Cambridge, MA: Harvard University Press.

Habermas, J. (1962, 1989, transl. T. Burger with the assistance of Frederick Lawrence). The structural transformation of the public sphere: An inquiry into a category of bourgeois society. Cambridge: Polity Press.

Habermas, J. (1984, 1987 trans. T. McCarthy). The theory of communicative action. Cambridge: Polity Press.

Hogan, P. C. (2003). The mind and its stories: Narrative universals and human emotions. Cambridge: Cambridge University Press.

Hughes, Helen M. (1940, 1981). News and the human interest story. New Brunswick: Transaction Books.

Kellner, Douglas (2003). Media spectacle. London and New York: Routledge. 


\section{PUBLIC RIGHT TO KNOW}

Kosinski, J. (1970). Being there. New York: Bantam Books.

Kundera, Milan (1984, trans. by M. H. Heim). The unbearable lightness of being. New York: Harper and Row.

Maza, S. (1996). Stories in history: Cultural narratives in recent works in European history. The American Historical Review. 101(5), 1493-1515.

Ong, W. J. (1982). Orality and literacy: The technologizing of the word (2nd ed.). New York: Routledge.

Postman, N. (1987). Amusing ourselves to death: Public discourse in the age of show business. London: Methuen.

Poynting, S. and Noble, G. (2003). 'Dog-whistle' journalism and Muslim Australians since 2001. Media International Australia. 109, 41-49.

Propp, V. (1968, trans. by L. Scott). Morphology of the folktale. Austin: University of Texas Press.

Proppian Fairy Tale Generator. (n.d.). Retrieved on 25 August 2008, from www.brown.edu/Courses/FR0133/Fairytale Generator/gen.html

Proppian Folktale Outline Generator v1.0. (n.d.). Retrieved on 25 August 2008, from www.stonedragonpress.com/wicca_201/vladimir_propp/oral_tradition_00_a. html

Strauss, D. F. (1835, 1970, trans. by Marian Evans). The life of Jesus critically examined. New York: Calvin Blanchard Press.

Sturken, Marita, (1997). Tangled memories: The Vietnam war, the AIDS epidemic and the politics of remembering. Berkeley, CA: University of California Press.

Sturken, Marita (2008). Memory, consumerism and media: Reflections on the emergence of the field. Memory Studies. 1(1), 73-78.

Thompson, John (1990). Ideology and modern culture: Critical social theory in the era of mass communication. Cambridge: Polity Press.

Tuchman, G. (1978). Making news: A study in the construction of reality. New York: Free Press.

Turner, V. (1981). Social dramas and stories about them. In W. J. T. Mitchell, (Ed.) On narrative (pp. 137-64). Chicago, IL: Chicago University Press.

Young, I.M. (2000). Inclusion and democracy. Oxford: Oxford University Press.

Zerubavel, E. (1999). Social mindscapes: An invitation to cognitive sociology. Cambridge, MA: Harvard University Press.

Zhong, C.-B., Galinsky, A., D. and Unzueta, M. M. (2008). Negational racial identity and presidential voting preferences. Journal of Experimental Social Psychology 44, 1563-1566.

Dr John Carr teaches and researches in communication, psychology and media studies at the University of Technology, Sydney. An earlier version of this paper was presented at the Public Right to Know Conference: 'Giving The People What They Want', in Sydney, 17-18 October 2008. john.carr@uts.edu.au 